\title{
Publicly Accessible Charging Site Host Recruitment During The EV Project
}

\author{
Idaho National Laboratory
}

July 2015

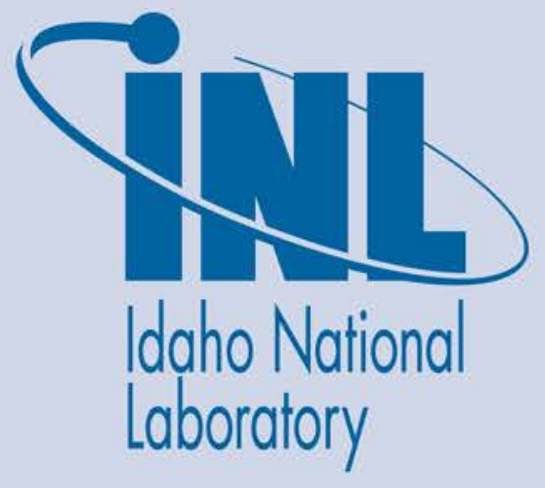

The INL is a U.S. Department of Energy National Laboratory operated by Battelle Energy Alliance 
INL/EXT-15-36334

\title{
Publicly Accessible Charging Site Host Recruitment During The EV Project
}

\author{
Idaho National Laboratory
}

July 2015

\section{Idaho National Laboratory \\ Idaho Falls, Idaho 83415}

http://www.inl.gov

\author{
Prepared for the \\ U.S. Department of Energy \\ Assistant Secretary for __, OR Office of \\ Under DOE Idaho Operations Office \\ Contract DE-AC07-05ID14517
}




\section{EVProject}

\section{Publicly Accessible Charging Site Host Recruitment During The EV Project}

July 2015

\section{Key Conclusions}

- The EV Project assumption that commercial hosts are essential to any meaningful expansion of publicly accessible charging was correct for the duration of The EV Project.

- The EV Project assumption that sufficient revenue could be generated to entice hosts into siting chargers based on a financial return was not correct for the duration of The EV Project.

- It became clear during the Project that other value streams beyond revenue were required to persuade hosts to install and maintain electric vehicle supply equipment (EVSE), as charging revenue alone was not sufficient to cover costs and allow expansion of charger networks.

- Other value streams for a host having an EVSE on their property were identified during The EV Project, but were only available for a limited time.

- Increased number of EV's on the road are necessary to encourage hosts to add chargers and enable expansion of charger networks.

\section{Introduction}

Achieving significant contributions to the US charging infrastructure from private enterprise is a complex and evolving challenge. The EV Project began under the premise that hosts were essential to expanding charging in publicly accessible (non-residential) locations. Based on that premise, there were a number of assumptions tested to recruit hosts for publicly accessible EVSE during the EV Project. This paper addresses the results of that testing during The EV Project and some of the adjustments that were made during the term of The EV Project to respond to actual results.

\section{Background}

Several assumptions were established at the start of The EV Project. One of the assumptions upon which the Project was based was that plug-in electric vehicle (PEV) drivers would require some form of charging infrastructure away from their residences. The basic need for infrastructure outside the home was assumed to be a key foundation of future EV growth. This assumption was based on surveys conducted as part of the EV Project ${ }^{1}$, on previous experience of The EV Project management team with charging infrastructure deployment and use, and on a strong desire by Nissan (which was the initial PEV partner of The EV Project), to have visible away-from-home charging infrastructure to support vehicle sales. It was assumed that PEV drivers would have range anxiety and have an expectation that charging infrastructure will be there for their use.

Early PEV adopters in The EV Project tended to have short commutes and to structure their EV driving within a defined radius that provided ready access to their home charger well before there was a need to connect for a charge ${ }^{2}$. However, this was not universally true, as The EV Project recorded drivers with high mileage accumulation and high frequency of charging away-from-home, even in the early days of The EV Project when publicly accessible charging infrastructure was scarce ${ }^{3}$. As can be seen in Figure 1, as the vehicle population participating in The EV Project grew, the frequency of use of publicly accessible infrastructure also grew. However, the use of publicly accessible charge infrastructure still provided only a small percent of the total energy for PEVs operating in The EV Project ${ }^{4}$.

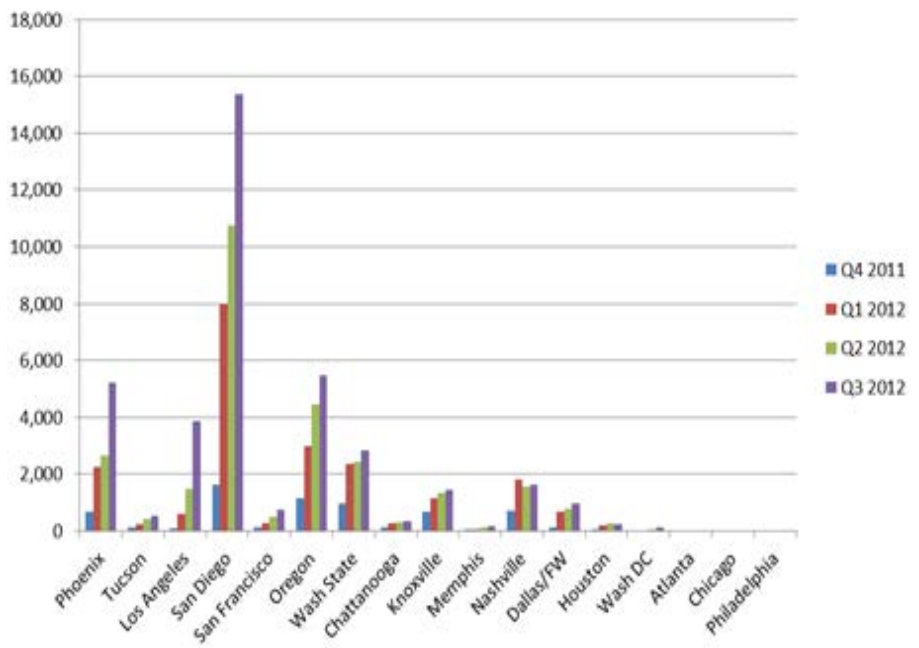

Figure 1. Number of non-residential charge events - Q4 2011 through Q3 2013.

\section{Need For Commercial Hosts}

The EV Project tested and validated the assumption that, for publicly accessible charging infrastructure to exist on a broad scale, a significant contribution from private commercial enterprises acting as hosts was required. Private hosts were consistently the best, most frequent and sometimes the only option for the placement of publicly accessible chargers in the EV Project. Not only were private enterprises willing to place a charger on their property in a location where an EV driver was likely to charge., but The EV Project data clearly showed that public charging most often occurred at places users visit for other 
reasons ${ }^{5}$ - locations where they can shop, eat, go to a movie, sporting event, use the internet, visit their doctor, handle a business meeting, use paid parking, etc. These desired locations are nearly all owned by private enterprise. From the start, The EV Project team recognized the need for private enterprise to host chargers. However as The EV Project progressed it became apparent that an even higher percentage of the publicly accessible chargers would be installed on private commercial property than was predicted in the initial planning for the EV Project.

The EV Project experience showed that publicly accessible infrastructure for charging will include AC Level 2 EVSE as well as DC Fast Chargers (DCFC). Chargers must be visible, at convenient locations, and appear on digital maps that can be compared to the PEV's current location. AC Level 2 chargers must be at attractive locations that offer "something to do" for a one- to two-hour period. It became clear from data and interviews ${ }^{6}$ during The EV Project that chargers located in places with no other reason for the user do be there experienced less charging. Toward the end of The EV Project, chargers with low use were visited, photographed and analyzed to determine why they had low use. Visibility and other factors played a role, but the conclusion was the absence of anything to do other than charging did not attract use. For DCFC, the need for the charger to be associated with an attraction was substantially less.

\section{Commercial Host Motivation}

Charging Site Hosts were an essential partner to The EV Project and a necessary ingredient to building a successful publicly accessible infrastructure. Commercial Charging Site Hosts had the locations and parking spaces that were most desirable for publicly accessible charging, and their business activities also provided a rational for a vehicle to be parked at the charging location for an hour or more. The EV Project focused on encouraging Charging Site Hosts to allow The EV Project to install and operate charging infrastructure at their business and focused on building a long-term partnership that would ensure ongoing availability of the infrastructure. The EV Project recognized that Charging Site Hosts needed to view chargers as an asset to their business and have a desire to add more.

The strongest motivation for Charging Site Hosts in The EV Project to install EVSE was to attract customers to their place of business. The EV Project recognized the need to encourage PEV drivers to "cross the threshold" of EVSE Charging Site Hosts and developed programs that encouraged PEV driver participation with Charging Site Hosts (see "Enhancements for Hosts"). Other intangible values were promoted to the host, such as the recognition of "being green", providing a benefit for employees, supporting an EV fleet, public/community contribution, etc.

\section{Siting Publicly Accessible Charging}

The EV Project assumed that for PEVs to be successful, commercial infrastructure would need to be robust and easily accessible and that AC Level 2 EVSE would need to be placed in malls and retail environments to offer many opportunities for a charge of an hour or two during the course of a normal day. Figure 2 presents an example of charger placement at a location where PEV drivers would spend time as well as a location where chargers are highly visible. The EV Project also assumed that DCFC chargers would need to be placed on travel corridors between urban areas and in heavily traveled routes within suburban areas.

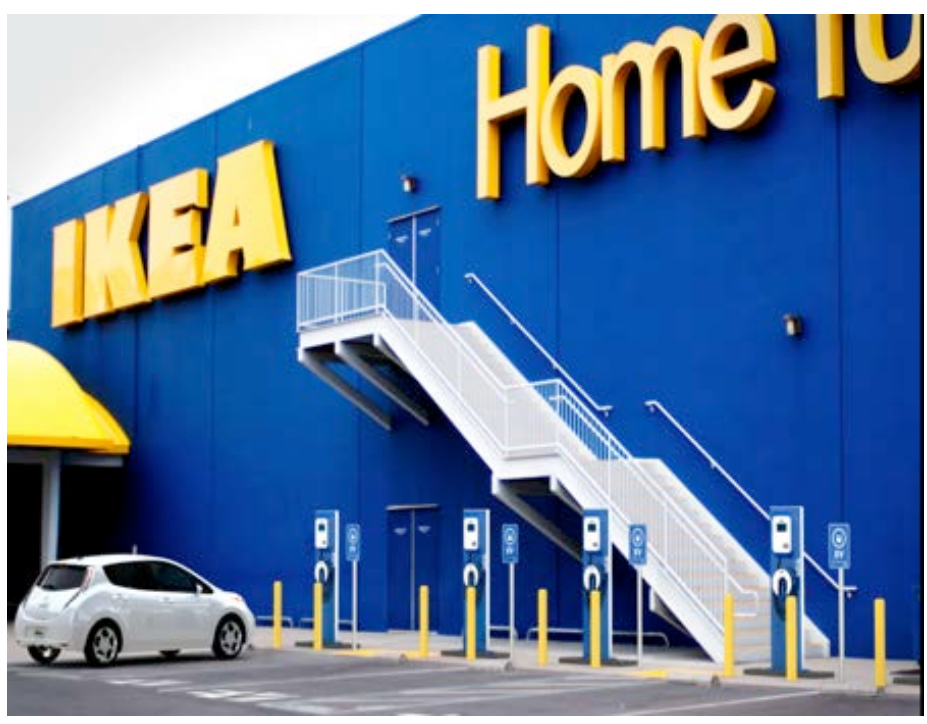

Figure 2. Retail EVSE installation.

At the start of The EV Project it was unclear how frequently PEV drivers would utilize publicly accessible charge infrastructure. Acknowledging that some level of infrastructure was required, The EV Project attempted to test various ideas defining the quantity and type of infrastructure that would serve the needs of PEV drivers as well as make an acceptable business case for Charging Site Hosts. The challenge was to determine the levels necessary to sustain and encourage the growth of PEVs. The EV Project team was concerned that if EVSE deployment was excessive, some of the infrastructure would languish unused and could discourage PEV adoption. Conversely, if EVSE deployment was insufficient, the proliferation of EVs could be slowed. The EV Project attempted to be judicious in its placement of charging infrastructure, using its Micro-Climate planning process to identify target areas for publicly accessible charge infrastructure ${ }^{7}$. 


\section{Commercial Host Relationships}

A significant issue for Charging Site Hosts in The EV Project was support to maintain a charger on their property, and the cost of that maintenance. The EV Project provided comprehensive services at no cost to the Charging Site Host during the project in order to mitigate these issues and facilitate the use of publicly accessible charging infrastructure deployment. Services offered to hosts by The EV Project included;

1. Maintenance of the EVSE,

2. Firmware and software upgrades,

3. Equipment upgrades as required,

4. Cellular Internet access for charge data collection,

5. Internet network support,

6. Call Center support,

7. Access to EVSE screen advertising,

8. Account reports,

9. Marketing, including coupons and other promotions,

10. Reservations, and

11. Reports on use and growth.

Enhancements for Hosts - To grow the public infrastructure The EV Project sought a formula that balanced the cost of operating and maintaining charge infrastructure with the revenue generated from the infrastructure. The challenges for matching revenue to cost during The EV Project included:

1. The costs of the AC Level 2 EVSE and DCFC were high due to low volume and a first-of-a-kind design ${ }^{5}$,

2. Low utilization of publicly accessible charging infrastructure,

3. Price competition from home charging, and

4. High value placed by hosts on retail parking locations.

Considering these factors, The EV Project determined, even before access fees were introduced, that there would not be sufficient revenue to cover the costs incurred by either The EV Project or the Charging Site Host in operating and maintaining publicly accessible charge infrastructure. As a result, early in The EV Project, value streams for Charging Site Hosts in addition to fee revenue were examined. These value streams included a combination of added value for the host and sources of potential additional revenue. The ideas examined included;

- Host coupons - A program was created for retail Charging Site Hosts to offer discounts to PEV drivers. For retail Charging Site Hosts, the greatest incentive to host a charging site was to have additional customers enter the business premises. Coupons, discounts and gifts provided a means to encourage this behavior. A variety of means to realize these functions such as a message on the EVSE, posting on a membership site, and follow-up emails were tested by The EV Project.

- $\quad$ Reservations - The ability for a user to schedule a visit to an EVSE was expected to help in expanding PEV range and ease of charging infrastructure use for PEV drivers. As a fee was anticipated for this function, and it was expected to marginally add to revenue. However, reservations were never implemented during the term of The EV Project

- Advertising - Advertising on the EVSE display screen and vinyl graphic wraps (Figure 3) on the charger itself generated another revenue stream for the Charging Site Host and The EV Project. Sales of this advertising were only achieved toward the end of The EV Project, so the knowledge gained and revenue generated was limited.

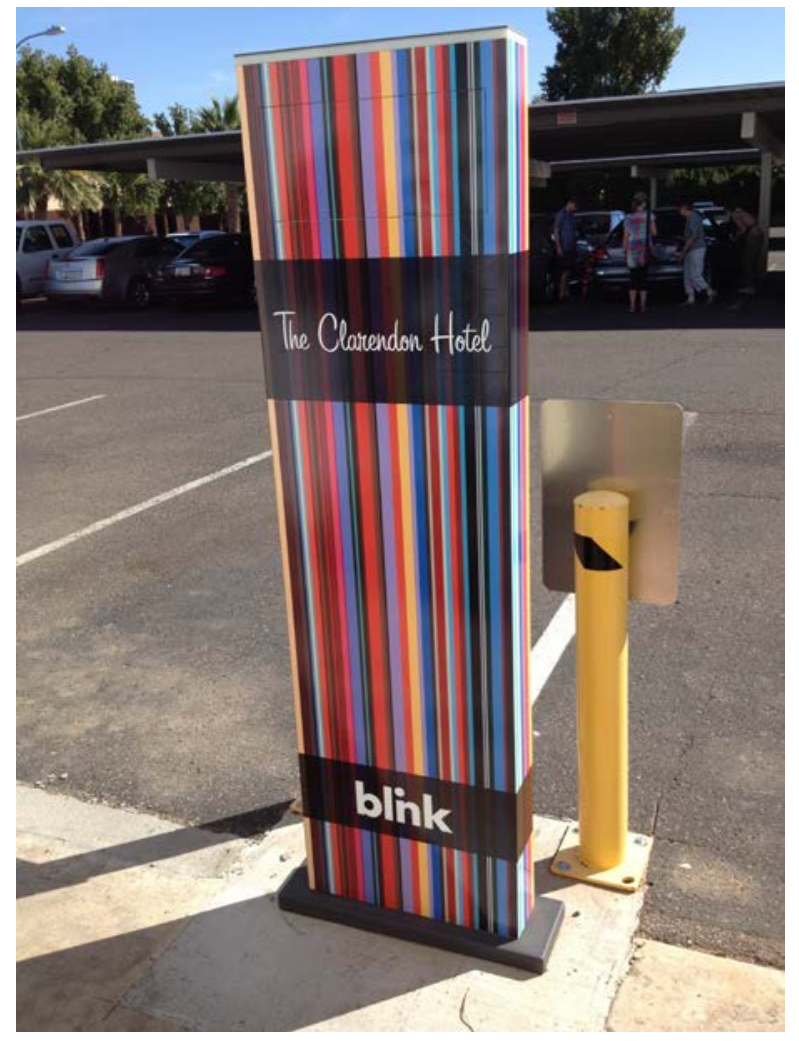

Figure 3. Clarendon Hotel charger vinyl wrap.

- Membership - The EV Project offered rewards and inducements to utilize publicly accessible charge infrastructure and to be a member of its "Blink" charger network, including frequent-user rewards and charging discounts to encourage use of publicly accessible charge infrastructure and to encourage concomitant patronage of the Charging Site Host business. Membership fees also represented a potential revenue source. 
- Fleets - Smart EVSE, as designed and operated by The EV Project, can facilitate management of PEVs operated in a fleet environment in a number of ways, from scheduling to tracking. Enhancements to the operation of The EV Project EVSE for management of fleet PEVs were planned, designed and implemented to encourage EVSE installation by fleets. This proved useful in convincing fleet management to install chargers during The EV Project.

Host Concerns - The EV Project offered to provide EVSE at no cost to the Charging Site Host, as well as pay a portion (limited to a pre-set amount) of the installation cost. This offer resulted in no or low cost installations for most Hosts. Hosts were approached in locations identified in the Micro-Climate ${ }^{\mathrm{TM}}$ planning process as locations suitable for EVSE. Additionally, national and regional retail chains that might commit to a large number of charger installations were solicited. However, even with financial incentives, recruiting Charging Site Hosts was difficult and in general fell short of targets.

The greatest cause for reticence on the part of potential Charging Site Hosts was concern over the lack of PEVs on the road. This "chicken and egg" concern was an issue for the entire duration of The EV Project. Additional concerns included costs to maintain the chargers after the conclusion of The EV Project and the need to comply with Americans With Disabilities Act (ADA) requirements. Based on The EV Project experience, the reaction of hosts to paying for some of the operating costs was inconsistent. A few indicated covering costs was not important. Others, particularly government entities, were strongly in favor of compensation to cover all of their costs.

Owners of commercial property, with limited parking spaces were loath to dedicate spaces to PEV charging. Further, they often expressed concern that their property would be subject to a period of construction for installation, which adds to general customer inconvenience, risks, insurance costs and is a distraction to operations.

Many Charging Site Hosts did not own the location in which they were doing business. This created additional complications to the execution of installation agreements for EVSE, due to the involvement of a $3^{\text {rd }}$ party. Whether the Charging Site Host owned the land or had a lease, there were often covenants with the other co-located tenants regarding the use of parking, modifications to the property, impact mitigation of site construction, and common electrical service which complicated EVSE installation.

Agreements - Participation in The EV Project required that an agreement be executed between the Charging Site Host and The EV Project. Amongst the terms of the agreement, the Charging Site Host was offered a portion of the revenue from access fees (typically 50\%), and an opportunity to share in future advertising revenue. The host would also be allowed to retain the AC Level 2 EVSE or have it removed at the end of The EV Project. The host agreed to allow the data from the EVSE to be collected by The EV Project and to participate when requested in surveys and other aspects of the Project. The hosts also agreed to provide and pay for the electricity which they expected would be offset by revenue.

\section{Host Fee-Price Summary}

The EV Project began by offering free charging units to participants in The EV Project. This was intended to encourage new PEV owners to familiarize themselves with the location and operation of publicly accessible charging infrastructure. The EV Project initially considered initiating fees for charging using a simple model based on a fee for each charger use. This initially seemed like a good solution as it was easy to program \& administer and easy for the user to understand. It quickly became clear, however, that the simplicity lead to many unintended complications and challenges. After reconsideration, The EV Project adopted a model based on time connected to the EVSE, (hourly for AC Level 2 and by the minute for DCFC use). The Blink EVSE were capable of managing fees based on connect time. Various practices were employed to improve customer acceptability, such as a delay time before the fee would be charged (a few minutes delay to assure the PEV driver desired to charge for a fee).

After the introduction of a fee plan, it became clear that some Charging Site Hosts desired to keep use of the EVSE at their site free. An option was included in the administration of the fee program to cover this contingency. This was done by collecting a monthly operation and maintenance fee from the Charging Site Host rather than sharing access fee revenue. Several Charging Site Hosts chose this option.

\section{Conclusions}

Many potential Charging Site Hosts required significant persuading to participate in The EV Project. They had financial concerns regarding installation costs, maintenance costs, operating costs, and the disruption to their business from construction. However, the fairly small number of PEVs in the community was the major concern for potential Charging Site Hosts. They were disinclined to provide dedicated parking spaces for vehicles that they were not seeing on the road, let alone in front of their business.

The EV Project employed a variety of incentives for Charging Site Hosts to make the opportunity to host charge infrastructure more attractive. First, the EVSE unit was free, and installation was substantially subsidized. In 
addition, The EV Project shared with the Charging Site Host, revenue collected from charger access fees, and offered programs such as coupons to attract customers to the Charging Site Host business. The EV Project also attempted to generate revenue through advertising on charger screens and using vinyl wraps on the chargers.

\section{About The EV Project}

The EV Project was the largest PEV infrastructure demonstration project in the world, equally funded by the United States Department of Energy (DOE) through the American Recovery and Reinvestment Act and private sector partners. The EV Project deployed over 12,000 AC Level 2 charging stations for residential and commercial use, as well as over 100 dual-port DC fast chargers, in 17 U.S. regions. Approximately 8,300 Nissan LEAFs ${ }^{\mathrm{TM}}$, Chevrolet Volts, and Smart ForTwo Electric Drive vehicles were enrolled in the project.

Project participants gave written consent for EV Project researchers to collect and analyze data from their vehicles and/or charging units. Data collected from the vehicles and charging infrastructure represented almost 125 million miles of driving and 4 million charging events. The data collection phase of The EV Project ran from January 1, 2011, through December 31, 2013. Idaho National Laboratory is responsible for analyzing the data and publishing summary reports, technical papers, and lessons learned on vehicle and charging unit use.

\section{Company Profile}

Idaho National Laboratory is one of DOE's 10 multi-program national laboratories. The laboratory performs work in each of DOE's strategic goal areas: energy, national security, science, and the environment. Idaho National Laboratory is the nation's leading center for nuclear energy research and development. Day-to-day management and operation of the laboratory is the responsibility of Battelle Energy Alliance.

For more information, visit avt.inl.gov/evproject.shtml and avt.inl.gov/chargepoint.shtml.

\section{References}

1. "How Do The EV Project Participants Feel About Charging Their EV Away From Home?" Lessons Learned, avt.inl.gov/evproject.shtml.

2. "What use patterns were observed for PEV drivers at publicly accessible AC Level 2 EVSE sites?" Lessons Learned, avt.inl.gov/evproject.shtml.

3. ibid

4. ibid

5. ibid

6. "How Do The EV Project Participants Feel About Charging Their EV Away From Home? " Lessons Learned, avt.inl.gov/evproject.shtml.

7. Charger Hardware Design \& Fabrication Lessons Learned By The EV Project" Lessons Learned, avt.inl.gov/evproject.shtml. 